University of New Hampshire

University of New Hampshire Scholars' Repository

Fall 1988

\title{
Consequences of Categorical Labeling of Preschool Children
}

Bruce L. Mallory

University of New Hampshire, bruce.mallory@unh.edu

Georgia M. Kerns

University of New Hampshire - Main Campus, Georgia.Kerns@unh.edu

Follow this and additional works at: https://scholars.unh.edu/educ_facpub

Part of the Special Education and Teaching Commons

\section{Recommended Citation}

Mallory, B.L., \& Kerns, G.M. (1988). Consequences of categorical labeling of preschool children. Topics in Early Childhood Special Education, 8(3), 39-50.

This Article is brought to you for free and open access by the Education at University of New Hampshire Scholars' Repository. It has been accepted for inclusion in Education Scholarship by an authorized administrator of University of New Hampshire Scholars' Repository. For more information, please contact Scholarly.Communication@unh.edu. 


\title{
Consequences of Categorical Labeling of Preschool Children
}

Bruce L. Mallory and Georgia M. Kerns, University of New Hampshire

\begin{abstract}
The use of categorical diagnostic labels prescribed in P.L. 94-142 with children below school age is examined in this article. National practices relative to categorical labeling are reviewed, and questions are posed concerning the consequences of categorical labeling for children from 3 to 6 years old. Data from the state of New Hampshire concerning the frequency of usage for specific categorical labels are presented and are found to be consistent with national trends. Data are presented on the number of children who transition from noncategorical early intervention programs serving children birth to 3 years into categorical preschool programs for children 3 through 5 years. Almost one-third of all children served in early intervention are found not to be eligible for preschool services because of the requirement for a categorical label. The roles of demographic factors related to place of residence, age, and local school policies in deciding who is eligible for services and what diagnostic category is assigned, were considered. Finally, the consequences of categorical labeling for children, parents, and programs are discussed.
\end{abstract}

Since Hobbs's (1975) seminal work on the classification of children with handicapping conditions, there has been much talk and little action. The diagnostic categories prescribed in P.L. 94-142, signed by President Ford in the same year Hobbs published his critique, seem to have become firmly entrenched in state-level special education policies. Soon after the enactment of the federal law, concerns were expressed that the use of categorical labels for children below 6 years would be inappropriate (Cohen, Semmes, \& Guralnick, 1979). These same concerns linger, reiterated most recently by Smith and Schakel (1986).

Reservations about the value of categorical labels for preschool children focus on damage to the chances for children's success in public school due to altered perceptions of their abilities on the part of pro- 
fessionals and parents, damage to their self-concept, and the inappropriate placement of children in self-contained, categorically grouped classrooms (Hobbs, 1975; Leigh, 1983; Mercer, Algozzine, \& Trifiletti, 1979; Palmer, 1983).

Currently, 40 states mandate services for children with educational handicaps ages 3 to 5 years (Garwood, 1987). All but eight of these states require that preschool children be diagnosed according to the categorical labels found in P.L. 94-142 (Smith \& Schakel, 1986). Noncategorical labeling practices include relying on a degree of delay formula that takes into account the discrepancy between the child's chronological age and developmental age in several domains, combining categorical and noncategorical approaches, and qualifying a nohcategorical label with descriptors such as mild/moderate or severe/profound (New Hampshire Department of Education, 1985). It will be important to observe how these practices change (if at all) in response to P.L. 99-457, which allows states to provide services to children birth through 5 years without assigning a categorical label (Lilly \& Shotel, 1987).

Seven states mandate special education services to children below 3 years old. Six of these apply the categorical P.L. 94-142 labels to infants and toddlers. One of these, lowa, also allows the provision of services to very young children who are identified as "deferred diagnosis" (Lilly \& Shotel, 1987).

Given the conflict between professional judgment and social policy concerning the appropriateness of categorical labeling of preschool children, it is important to analyze the consequences of such labeling. Because of the differences in service delivery systems for children below 3 years old and those between 3 and 6, we need to understand (a) what happens when children move from noncategorical early intervention programs into categorical preschool programs, (b) what labels are most likely to be assigned to preschool children, (c) how those labels might change as children get older, and (d) what the potential consequences of these phenomena are for the affected children and their families.

The exploratory analysis that follows draws upon data from New Hampshire, a relatively small, ethnically homogeneous state undergoing a shift from a predominantly rural economic and cultural base to a more industrial, suburban, and urban environment. New Hampshire law closely parallels P.L. 94-142 and mandates a free, appropriate public education for all children with educational handicaps beginning at age 3 . Like most other states, New Hampshire requires that all children who receive special education be found to have an education handicap consistent with the diagnostic categories in P.L. 94-142. New Hampshire also 
provides services to handicapped and at-risk infants and toddlers through community programs funded by the state's Division of Mental Health and Developmental Services. These early intervention services, however, are less than universal in their coverage. In 1987, 530 children were enrolled in such programs. This represents about $1.2 \%$ of the total birth to 3 population, well below the expected prevalence rates of $6 \%$ to 7\% (Fine \& Swift, 1986; Garland, Stone, Swanson, \& Woodruff, 1981).

\section{The Transition from Early Intervention to Preschool Programs}

Early intervention programs in New Hampshire serve children who are at medical, biological, or environmental risk. The definitions of these risk categories are based on Tjossem's (1976) categories of vulnerable infants. These descriptors allow a great deal of latitude in determining who is eligible for early intervention services, resulting in a broad mix of children, including high-risk premature newborns, children born with congenital anomalies, technology-dependent children, and children from social environments where there is a strong predisposition for inadequate stimulation or care.

Among the 15 programs providing early intervention services, there is considerable variation as to the types of children enrolled within these general categories. Those programs in urban areas, with close ties to neonatal hospital facilities, tend to serve biologically and medically atrisk children, with children at environmental risk likely to be placed on waiting lists or to be offered maintenance services such as monthly home visits or telephone calls. Programs in less densely populated areas, where there is less reported incidence of severe disabilities, tend to serve infants and toddlers at environmental risk.

It is at the point of transition from early intervention to preschool programs that the matter of categorical labeling first affects young children and their families. In order for the 3-year-old previously served by early intervention to continue receiving services under the auspices of the public school, he or she must be found to be educationally handicapped and assigned one of the 11 diagnostic categories found in federal and state regulations. For some children, this requires that a specific label be applied for the first time, as they were previously simply referred to as at risk.

During the 1986-87 fiscal year, about 300 children who were enrolled in early intervention programs turned 3 years old, requiring that 
they enter either a public school special education program or, if not diagnosed as educationally handicapped, enroll in a generic preschool program for which parents must pay tuition costs. Some children not found to be eligible for special education are placed in compensatory programs such as Head Start, and some continue to receive clinical therapy through parent or third-party payment.

We were able to collect information concerning the transition process from 13 of the 15 programs. Of those children who "aged out" of early intervention programs, $69.9 \%$ were found to be educationally handicapped by their local school district's Pupil Placement Team (PPT). The remaining $30.1 \%$ were found not to be educationally handicapped, and therefore were no longer eligible for special services. This statewide figure was rather variable at the program level. At one extreme, a program that serves a large number of children at environmental risk had only 3 out of 29 3-year-olds (10\%) diagnosed as educationally handicapped. This program serves a predominantly rural area and sends childreninto a school district with a reputation for refusing to provide special education to either mildly or profoundly handicapped students. At the other extreme, three programs reported that $100 \%$ of their 3 year-olds were identified by PPTs as educationally handicapped. Thus the chances for receiving continued services once a child turns 3 may depend on the child's developmental status and the actions of the school district's PPT, which is determined partially by the ideology of the school district administration as well as the skills and knowledge possessed by the PPT members relative to preschool-aged children. These preliminary data suggest that systemic and ideological factors play a role in the labeling process in addition to more child-specific variables.

This mixture of developmental, political, and technical factors is associated with variations from region to region within the state. The potential exists for unequally distributed resources for young children with developmental needs and their families. For those children who do receive services from their local schools, the diagnostic process remains conflicted.

\section{Labels Assigned to Preschool Children}

By the end of the 1986-87 school year, 1,120 children between 3 and 6 years old were assigned one of the diagnostic labels prescribed by P.L. 94-142. This represents $2 \%$ of the total population of this age group, compared to the national average of $3 \%$ (United States Government 
Accounting Office, 1981). Table 1 indicates the number and percentage of children within each diagnostic category. Note that the label speech and language impaired is by far the most frequently used category.

The labeling patterns found in New Hampshire are consistent with those found nationally with respect to the use of the speech and language label, but not in the other most prevalent categories. Nationally, the percentages of children from 3 through 5 years with an educational handicap and who are diagnosed with speech and language impairment, mental retardation, learning disability, and emotional disturbance are $70.5 \%, 7.8 \%, 7.8 \%$ and $2.4 \%$, respectively (U.S. Department of Education, 1986). These compare with New Hampshire's proportions in the same categories of $75.6 \%, 2.6 \%, 1.4 \%$, and $1.1 \%$, respectively.

The disproportionate use of the speech and language label has several possible explanations. It may simply be that this does, in fact, represent reality in New Hampshire. A sparsely distributed population, with a significant portion of French-Canadian families whose native language is French, combined with a harsh winter that is associated with untreated

Table 1. Labels Assigned to Preschool Children

\begin{tabular}{|c|c|c|c|c|}
\hline \multirow[b]{2}{*}{ Diagnostic Category } & \multicolumn{4}{|c|}{ Age } \\
\hline & $\begin{array}{c}3 \\
(n=199)\end{array}$ & $\begin{array}{c}4 \\
(n=416)\end{array}$ & $\begin{array}{c}5 \\
(n=505)\end{array}$ & $\begin{array}{c}\text { Total } \\
(n=1120)\end{array}$ \\
\hline Speech and Language Impaired & $\begin{array}{c}138 \\
(69.3 \%)\end{array}$ & $\begin{array}{c}312 \\
(75.0 \%)\end{array}$ & $\begin{array}{c}397 \\
(78.6 \%)\end{array}$ & $\begin{array}{c}847 \\
(75.6 \%)\end{array}$ \\
\hline Multihandicapped & $\begin{array}{c}23 \\
(11.6 \%)\end{array}$ & $\begin{array}{c}32 \\
(7.7 \%)\end{array}$ & $\begin{array}{c}22 \\
(4.4 \%)\end{array}$ & $\begin{array}{c}77 \\
(6.9 \%)\end{array}$ \\
\hline Other Health Impaired & $\begin{array}{c}10 \\
(5.0 \%)\end{array}$ & $\begin{array}{c}19 \\
(4.6 \%)\end{array}$ & $\begin{array}{c}23 \\
(4.6 \%)\end{array}$ & $\begin{array}{c}52 \\
(4.6 \%)\end{array}$ \\
\hline Orthopedically Impaired & $\begin{array}{c}13 \\
(6.5 \%)\end{array}$ & $\begin{array}{c}14 \\
(3.4 \%)\end{array}$ & $\begin{array}{c}20 \\
(4.0 \%)\end{array}$ & $\begin{array}{c}47 \\
(4.2 \%)\end{array}$ \\
\hline Mentally Retarded & $\begin{array}{c}2 \\
(1.0 \%)\end{array}$ & $\begin{array}{c}11 \\
(2.6 \%)\end{array}$ & $\begin{array}{c}16 \\
(3.2 \%)\end{array}$ & $\begin{array}{c}29 \\
(2.6 \%)\end{array}$ \\
\hline Specific Learning Disability & $\begin{array}{c}3 \\
(1.5 \%)\end{array}$ & $\begin{array}{c}7 \\
(1.4 \%)\end{array}$ & $\begin{array}{c}6 \\
(1.2 \%)\end{array}$ & $\begin{array}{c}16 \\
(1.4 \%)\end{array}$ \\
\hline Visual Handicap & $\begin{array}{c}4 \\
(2.0 \%)\end{array}$ & $\begin{array}{c}8 \\
(1.9 \%)\end{array}$ & $\begin{array}{c}4 \\
(.79 \%)\end{array}$ & $\begin{array}{c}16 \\
(1.4 \%)\end{array}$ \\
\hline Deaf & $\begin{array}{c}5 \\
(2.5 \%)\end{array}$ & $\begin{array}{c}5 \\
(1.2 \%)\end{array}$ & $\begin{array}{c}2 \\
(.40 \%)\end{array}$ & $\begin{array}{c}12 \\
(1.1 \%)\end{array}$ \\
\hline Emotional Handicaps & $\begin{array}{c}0 \\
(0 \%)\end{array}$ & $\begin{array}{c}5 \\
(1.2 \%)\end{array}$ & $\begin{array}{c}7 \\
(1.4 \%)\end{array}$ & $\begin{array}{c}12 \\
(1.1 \%)\end{array}$ \\
\hline Hard of Hearing & $\begin{array}{c}1 \\
(.50 \%)\end{array}$ & $\begin{array}{c}2 \\
(.48 \%)\end{array}$ & $\begin{array}{c}6 \\
(1.2 \%)\end{array}$ & $\begin{array}{c}9 \\
(.8 \%)\end{array}$ \\
\hline Deaf-Blind & $\begin{array}{c}0 \\
(0 \%)\end{array}$ & $\begin{array}{c}1 \\
(.24 \%)\end{array}$ & $\begin{array}{c}2 \\
(.40 \%)\end{array}$ & $\begin{array}{c}3 \\
(.27 \%)\end{array}$ \\
\hline
\end{tabular}


otitis media, may result in a primary handicapping condition of speech and language impairment.

On the other hand, alternative explanations seem tenable. From a technical point of view, the speech and language impairment may be a presenting symptom of more global developmental delays or specific cognitive, sensory, and/or motor impairments. The assessment instruments and the skills of those doing the assessment may not be sensitive enough to detect underlying causes. Or, from a sociological perspective, the speech and language label may be viewed by both professionals and parents as less stigmatizing than more discrete categories such as mental retardation, orthopedic impairment, or learning disability. Because the labeling process occurs early in a child's educational career, and the parents may be in the initial process of adjusting to their child's special needs, the speech and language impaired label is perceived to be easier to swallow and less likely to interfere with the embryonic parentprofessional relationship.

Related to this interpretation is what can be called the "child advocacy rationale." This approach was embodied in the remarks of one preschool administrator in another state who explained to us why she assigns the speech and language impaired label to all the children in her program, regardless of their primary handicapping condition. She believes that this was the most nebulous category available and conveyed the least amount of information about a child to the next placement (kindergarten or first grade). This resulted in a more careful individual assessment of each child's needs at public school entry. The administrator felt that the use of more discrete labels, even when they accurately reflected the child's status, would obviate an individual assessment, resulting in automatic placement in a self-contained program corresponding to the child's previously assigned label (e.g., educable mental retardation class, physically handicapped class, etc.).

Whatever the reason, there are far more preschool children labeled as speech and language impaired than would be expected. The pattern for preschool children is very different from that of school-age children.

\section{How Labels Change as Children Get Older}

Figure 1 demonstrates the proportional changes that occur in four diagnostic categories as children move from preschool to school age (New Hampshire Special Education Information System, 1987). Both 


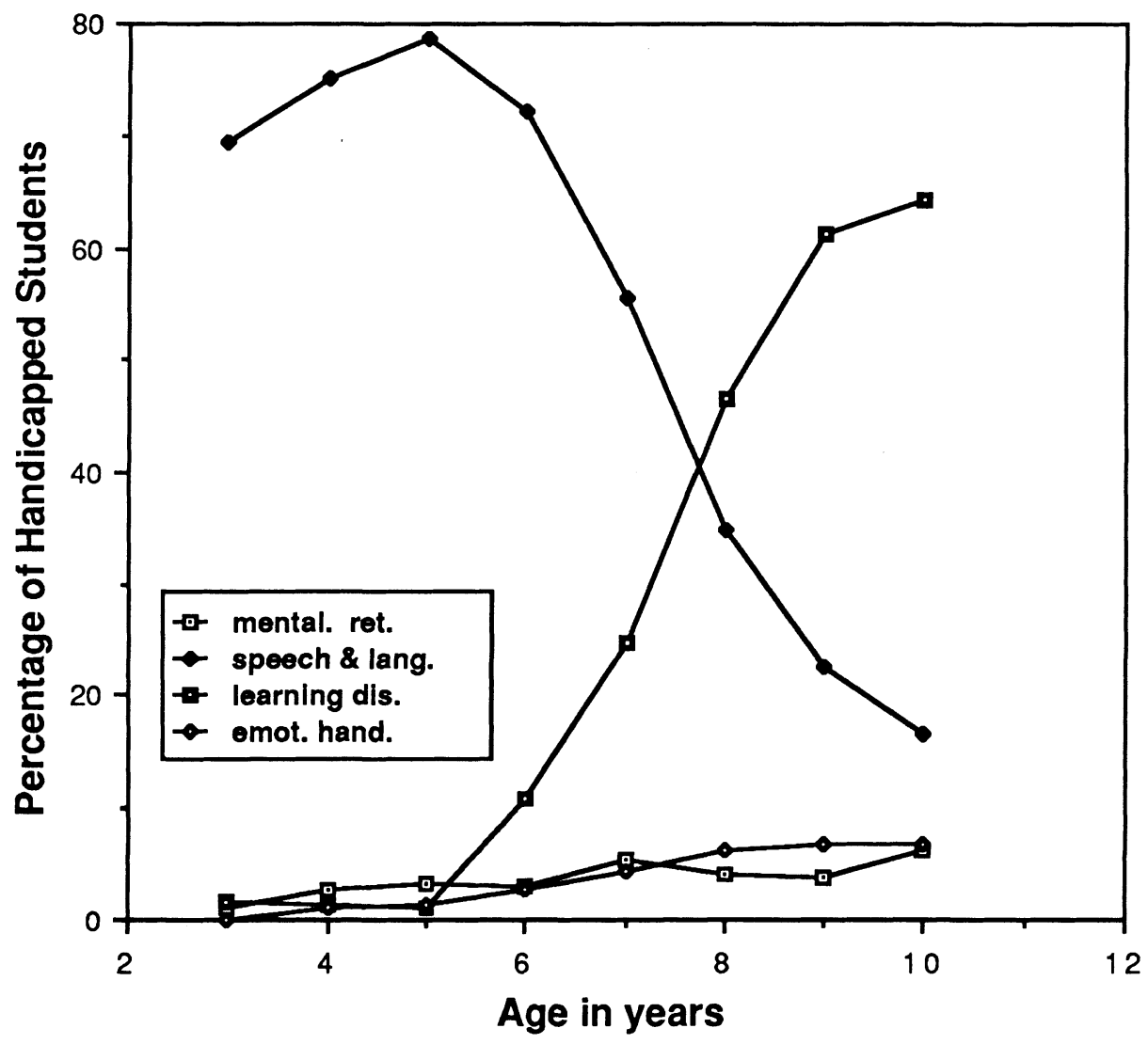

Figure 1. Changes in diagnostic categories as a function of age.

the speech and language impaired and learning disabled curves clearly indicate the changes that are associated with age. Because data were not readily available, we were unable to conduct the analysis that would be necessary to determine what portion of the newly labeled children with learning disabilities were previously identified as speech and language impaired. One state consultant (Pierce, personal communication, 1987) estimated that $50 \%$ of preschool children originally diagnosed as speech and language impaired were relabeled in the primary grades as learning disabled. If that is the case, then most of the decline in the number of speech and language impaired children that begins at age 7 (see Figure 1) would be due to rediagnosis rather than successful remediation. It appears that the other diagnostic categories most susceptible to socially grounded definitions (mental retardation and emotional handicaps) are 
not as affected by the rediagnosis of preschool children with speech and language impairments. The relative changes in incidence rates for the four categories depicted in Figure 1 are consistent with national patterns. For example, the national percentage of children labeled speech and language impaired drops from $70.5 \%$ of 3 - to 5 -year-olds to $40.9 \%$ of 6 to 11-year-olds. Those labeled learning disabled increase from $7.8 \%$ of 3- to -5-year-olds to $38.2 \%$ of 6- to -11-year-olds (U.S. Department of Education, 1986).

\section{Consequences of Categorical Labeling}

Categorical labeling of young children may have an impact on everyone involved in the process-the child, the parent, the early intervention program, the preschool program, and ultimately the elementary school into which such children are placed. Categorical labeling may create difficulties in various ways.

There are several consequences for children as they reach age 3. First, on receiving a categorical label that may reflect only one area of need, the child may not receive all of the services required. For example, due to policies in some school systems, children having a speech and language impaired label may receive little or no occupational therapy even when it is appropriate; that is, the label, not individual needs, determines the array of services to be provided. Second, almost one-third of children served by early intervention are no longer eligible for services when they turn 3 years old. The resulting gap in services creates the possibility that more intensive special education is required at school entry at age 5 or 6 than would have otherwise been necessary. This may be especially true in rural, isolated areas where services such as Head Start and private preschool programs are less available. Finally, many children who are deemed eligible for special education services receive those services in self-contained programs associated with a particular diagnostic category (New Hampshire Special Education Information System, 1987). These children are often totally isolated from their peers without handicaps and are subjected to long bus rides in order to get to and from regional service centers.

Parents may also experience difficulties due to the categorical labeling of their young children. One concern noted by Kerns (1987) in her survey of parents in New Hampshire was the perception that assigning a label forces parents to assume a deficit orientation, focusing for the first time on their child's disability rather than abilities. Closely allied with 
this perception is the real possibility of changing expectations. While the child is labeled as at risk or developmentally delayed, parents, as well as professionals, may maintain a more optimistic prognosis for eventual remediation. When a label of mental retardation or learning disability is assigned, adults will continue to work with the child but within an expectation set that assumes impaired and limited development. The label serves as the explanation for limited development, creating a tautology that may well be false.

This view should be tempered by an understanding of the possible value of categorical labels from a parent's point of view. Featherstone (1980) describes the relief felt by many parents when they finally received a diagnostic label for their children. The uncertainty, the inability to communicate easily with other family members, and conflicting messages from professionals are ameliorated when a categorical label is assigned. What is important is that the label be accurate and not serve as a substitute either for an honest appraisal or a more complex assessment than discrete labels are capable of conveying. And any relabeling that occurs at elementary school entry should be based on real changes in a child's developmental status, not on social, political, or economic factors.

Categorical labeling of young children also affects professionals. Early intervention staff develop close relationships with children and their families. The assignment of a diagnostic label at age 3 may be viewed as a sign of failure or an indication that the services provided were not appropriate. Similarly, preschool staff may be forced to assume the role of "bearer of bad news" as diagnostic labels are assigned to young children entering their programs. This role would not be conducive to establishing positive rapport with parents early in the placement process.

\section{Conclusions}

New Hampshire, like most states that mandate special education services for preschool children with special needs, uses a system of categorical labels based on those prescribed in P.L. 94-142. Many of these children enter special education programs from early intervention programs that use at-risk definitions of need rather than categorical labels. Additionally, there are many children who, although provided services as infants and toddlers, no longer qualify at age 3 due to the requirements for categorical diagnoses. 
Demographic differences were noted in the types of at-risk children served by early intervention programs, with rural areas more frequently providing services to children at environmental risk. Differences were also noted in the proportion of children discharged from early intervention at age 3 who were then eligible for special education services.

Of those children identified as needing special education, the most frequent diagnosis was speech and language impairment. A number of explanations are plausible, including perceived stigma and the inadequate technology of early childhood assessment. The large portion of children labeled speech and language impaired beginning at age 3 decreases drastically at the point of elementary school entry, with a concurrent increase in numbers of children diagnosed as learning disabled.

The phenomena described here will potentially be ameliorated by the implementation of P.L. 99-457. The ability of states to use a noncategorical approach and still receive federal funds for 3-to 5-year-old children could significantly alter the demographic patterns found in New Hampshire and elsewhere. Of primary concern is the apparent arbitrariness that presently characterizes the diagnosis of preschool children. One way to accomplish this is to allow both categorical and noncategorical diagnoses, so that any particular label, such as speech and language impairment, is not used as a catch-all for children with global or complex developmental delays. This would allow for the use of discrete labels when appropriate and noncategorical labels until school entry, when the demands of the academic setting make clearer the nature of a child's educational handicap.

The use of a generic term such as at risk or developmentally delayed would be only a partial solution to a complex problem. The operational definition of these terms has never been uniformly specified, so discrepancies across children and communities would persist. Without concurrent advances in assessment procedures and the skills of those who do assessment, the problems associated with categorical labels might simply generalize to these generic terms. Measures of cost-effectiveness and program impact also would be problematic. And the transition at age 6 from preschool programs into primary grades could involve problems similar to those now occurring at age 3 . Smith (1980) projected increased coverage and costs associated with generic categories. On the other hand, follow-up studies of the efforts of early childhood intervention with children who could be described as at environmental risk generally show positive and lasting effects (Lazar \& Darlington, 1979; McNulty, Smith, \& Soper, n.d.) and long-term cost savings (Schweinhart, Berrueta-Clement, Barnett, Epstein, \& Weikert, 1985). Thus the more 
inclusive coverage associated with a label such as at risk for children 3 to 6 could result in a repetition of transition problems at primary school entry because of the categorical requirements of school-age programs. But there are demonstrated benefits of such an approach. This is a question to be resolved partially through the policy-making process.

The consideration of categorical labeling of young children raises more questions than it answers. Areas of future research should consider the practices that early intervention and preschool programs use to assess young children, to provide services based on individual needs rather than diagnostic categories, and to assist children and their families in the process of transition from one program to another. In analyzing these practices, geographic, ideological, and social factors must be taken into account. Longitudinal changes in children's diagnoses must also be examined to determine whether children are being discharged from special education or simply being assigned to a different category that may be as nebulous and socially defined as the first.

\section{References}

Cohen, S., Semmes, M., \& Guralnick, M. J. (1979). Public Law 94-142 and the education of preschool handicapped children. Exceptional Children, 45(4), 279-285.

Featherstone, H. (1980). A difference in the family: Living with a disabled cbild. New York: Basic Books.

Fine, M. A., \& Swift, C. F. (1986). Young handicapped children: Their prevalence and experiences with early intervention services. Journal of the Division for Early Childbood, 10(1), 73-83.

Garland, C., Stone, N., Swanson, J., \& Woodruff, G. (Eds.). (1981). Early intervention for children with special needs and their families: Findings and recommendations (Westar Series Paper No. 11). Seattle: University of Washington.

Garwood, S. G. (1987). Political, economic, and practical issues affecting the development of universal early intervention for handicapped infants. Topics in Early Childhood Special Education, 7(2), 6-18.

Hobbs, N. (1975). The futures of children. San Francisco: Jossey-Bass.

Kerns, G. M. (1987). Transition for young children with special needs in New Hampshire: Perceptions of parents and early intervention program directors. Unpublished doctoral dissertation, University of Kansas, Lawrence.

Lazar, I., \& Darlington, R. B. (1979). Lasting effects after preschool. Washington, DC: U.S. Department of Health, Education and Welfare.

Leigh, J. E. (1983). Early labeling of children: Concerns and alternatives. Topics in Early Childhood Special Education, 3(3), 1-6.

Lilly, T. J., \& Shotel, J. R. (1987). Legal issues and the handicapped infant: From policy to reality. Journal of the Division for Early Childbood, 12(1), 4-12.

McNulty, B. A., Smith, D. B., \& Soper, E. W. (n.d.) Effectiveness of early special education for bandicapped cbildren. Denver, Colorado Department of Education. 
Mercer, C., Algozzine, B., \& Trifiletti, J. J. (1979). Early identification: Issues and considerations. Exceptional Children, 46(1), 52-54.

New Hampshire Department of Education. (1985). Coding Committee issues paper. Concord, NH: Department of Education.

New Hampshire Special Education Information System. (1987, April). Census of educationally bandicapped students. Concord, NH: Department of Education.

Palmer, D. J. (1983). An attributional perspective on labeling. Exceptional Children, 49(5), 423-429.

Schweinhart, L. J., Berrueta-Clement, J. R., Barnett, W. S., Epstein, A. S., \& Weikart, D. P. (1985). Effects of the Perry Preschool Program on youths through age 19: A summary. Topics in Early Childhood Special Education, 5(2), 26-35.

Smith, B. J. (1980). Policy options related to the provision of appropriate early intervention services for very young exceptional children and their families. Reston, VA: Council for Exceptional Children.

Smith, B. J., \& Schakel, J. A. (1986). Noncategorical identification of preschool handicapped children: Policy issues and options. Journal of the Division for Early Childhood, 11(1), 78-86.

Tjossem, T. D. (Ed.). (1976). Intervention strategies for bigh risk infants and young children. Baltimore: University Park Press.

United States Department of Education. (1986). Eighth annual report to Congress on the implementation of the Education of the Handicapped Act, Vol. I. Washington, DC: Division of Educational Services and Special Education Programs.

United States Government Accounting Office. (1981). Disparities still exist in who gets special education. Washington, DC: Government Printing Office. 